This is an electronic reprint of the original article. This reprint may differ from the original in pagination and typographic detail.

Author(s): Marushkevich, Kseniya; Khriachtchev, Leonid; Räsänen, Markku; Melavuori, Mia; Lundell, Jan

Title: $\quad$ Dimers of the Higher-Energy Conformer of Formic Acid: Experimental Observation

Year: $\quad 2012$

Version:

Please cite the original version:

Marushkevich, K., Khriachtchev, L., Räsänen, M., Melavuori, M., \& Lundell, J. (2012). Dimers of the Higher-Energy Conformer of Formic Acid: Experimental Observation. The Journal of Physical Chemistry A, 116(9), 2101-2108.

https://doi.org/10.1021/jp209714e

All material supplied via JYX is protected by copyright and other intellectual property rights, and duplication or sale of all or part of any of the repository collections is not permitted, except that material may be duplicated by you for your research use or educational purposes in electronic or print form. You must obtain permission for any other use. Electronic or print copies may not be offered, whether for sale or otherwise to anyone who is not an authorised user. 


\title{
Dimers of the Higher-Energy Conformer of Formic Acid: Experimental Observation
}

\author{
Kseniya Marushkevich, ${ }^{\dagger}$ Leonid Khriachtchev, ${ }^{*}{ }^{\dagger}$ Markku Räsänen, ${ }^{\dagger}$ Mia Melavuori, ${ }^{\dagger}$ and Jan Lundell ${ }^{\ddagger}$ \\ ${ }^{\dagger}$ Department of Chemistry, University of Helsinki, P.O. Box 55, FIN-00014 Finland \\ ${ }^{\ddagger}$ Department of Chemistry, University of Jyväskylä, PL 35, FIN-40014 Finland
}

Supporting Information

ABSTRACT: We report on the first experimental observation of formic acid dimers composed of two molecules of the higher-energy cis conformer. The cis-cis formic acid dimers are prepared in an argon matrix by selective vibrational excitation of the ground state trans conformer (deuterated form HCOOD) combined with thermal annealing of the matrix at about $30 \mathrm{~K}$. Five cis-cis formic acid dimers are predicted by ab initio calculations (interaction energies from -16.9 to $-27.2 \mathrm{~kJ} \mathrm{~mol}^{-1}$ ), and these structures are used for the assignment of the experimental spectra. Selective vibrational excitation of the obtained cis-cis dimers leads to the formation of several trans-cis dimers, which supports the proposed assignments.

\section{INTRODUCTION}

Formic acid ( $\mathrm{HCOOH}, \mathrm{FA})$ is the simplest organic acid attracting significant research and industrial interest. This species has been found in the interstellar medium ${ }^{1,2}$ and in the coma of the Hale-Bopp comet. ${ }^{3}$ It has been suggested that it may be a key compound in the formation of glycine $\left(\mathrm{NH}_{2} \mathrm{CH}_{2} \mathrm{COOH}\right)$ in the interstellar medium. ${ }^{4}$ Formic acid may be considered as a building block of biomolecules, and it also serves as a model for the properties of amino acids. ${ }^{5,6}$ Atmospheric FA influences $\mathrm{pH}$-dependent chemical reactions in the Earth clouds and it is the major acidic component of rain. ${ }^{7}$ FA is an important oxygenated volatile organic compound. $^{8}$ The identified FA sources include biomass burning, biogenic emissions from vegetation and soils, secondary production from organic precursors, and emissions from motor vehicles. 9

Two possible conformers of FA (trans and cis) differ by the orientation of the hydroxyl group $(-\mathrm{OH})$. The trans conformer is lower in energy by ca. $1365 \mathrm{~cm}^{-1}$ than the cis form, ${ }^{10}$ which yields the Boltzmann population ratio $N_{\text {cis }} / N_{\text {trans }}$ of $1.4 \times 10^{-3}$ at room temperature. The higher-energy cis form can be efficiently prepared in rare-gas matrices by selective vibrational excitation of trans-FA. ${ }^{11,12}$ The higher-energy conformer decays back to the ground-state form via tunneling of the $-\mathrm{OH}$ hydrogen atom. ${ }^{12,13}$ The lifetime of the higher-energy cis conformer strongly depends on the surrounding, changing from $6.25 \mathrm{~h}$ in a nitrogen matrix ${ }^{14}$ to $75 \mathrm{~min}$ in a xenon matrix ${ }^{13}$ and to $5 \mathrm{~s}$ in a neon matrix. ${ }^{15}$ The higher-energy conformer of deuterated FA (HCOOD) is very stable compared to cis$\mathrm{HCOOH}^{13,16}$

The FA molecules can form a number of dimers stabilized by intermolecular hydrogen bonding. The trans-trans dimers have been extensively studied theoretically. ${ }^{17-23}$ Several such dimers have been observed experimentally in the gas phase, ${ }^{24-26}$ raregas matrices $^{17,20,27-31}$ and helium nanodroplets. ${ }^{32}$ A number of mixed trans-cis dimeric structures were also predicted ${ }^{17,23,33}$ and observed experimentally. ${ }^{17,30,31}$ Most of the predicted trans-trans and trans-cis dimers have been prepared and identified in our matrix-isolation experiments. ${ }^{17,30,31}$ The information on the cis-cis dimers is sparse. To our knowledge, only two cis-cis dimeric structures of FA have been calculated by Roszak et al. ${ }^{21}$ and no direct experimental observation of these structures has been reported. Shimizu and Goncharov et al. have tentatively suggested that high-pressure FA solid may consist of infinite chains of hydrogen bonded molecules in the cis conformation. ${ }^{34,35}$ Recently, a solid constituted of the higher-energy conformer of FA has been studied. ${ }^{36}$

In the present work, we report on the first experimental observation of dimers composed of the higher-energy FA conformer. The experiments are performed in argon matrices. In order to prepare the cis-cis dimers, we combine selective vibrational excitation to promote the trans-to-cis conformational change and thermal annealing to produce dimers. The identification of novel structures is based on ab initio calculations and selective vibrational excitation of the cis-cis dimers.

\section{COMPUTATIONAL METHODS AND RESULTS}

The equilibrium geometry and harmonic vibrational frequencies of trans- and cis-FA monomers, trans-trans, trans-cis, and cis-cis dimers, and complexes of trans- and cis-HCOOD with $\mathrm{D}_{2} \mathrm{O}$ (tFAW and cFAW) were calculated using the second-

Received: October 10, 2011

Revised: January 23, 2012

Published: January 26, 2012 
order Møller-Plesset perturbation (MP2) method with the 6$311++\mathrm{G}(2 \mathrm{~d}, 2 \mathrm{p})$ basis set. This level of theory is known to reproduce well the experimental vibrational properties of trans-trans and trans-cis FA dimers. ${ }^{17}$ All calculations were performed using Gaussian 03 package. ${ }^{37}$ The counterpoise method was used to account for the basis set superposition error (BSSE), ${ }^{38}$ and the zero-point energies (ZPE) were included. Six trans-trans and five trans-cis structures were studied earlier by the same theoretical method (Figure S1a and S1b). ${ }^{17}$ In the present work, an additional trans-cis dimer tc6 is found (Figure S1c) which was not reported in ref 17 . The tFAW and cFAW geometries are taken from ref 39.

Five stable cis-cis dimeric structures are found on the potential energy surface (PES) (Figure 1). Four cis-cis dimers

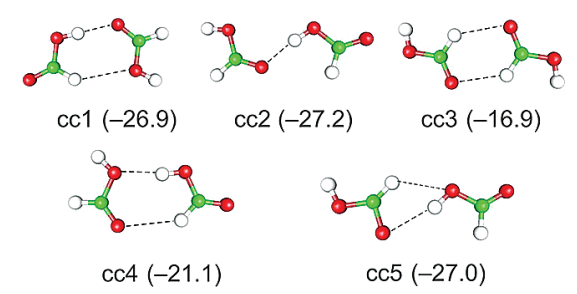

Figure 1. Calculated structures of the cis-cis formic acid dimers. The interaction energies (in $\mathrm{kJ} \mathrm{mol}^{-1}$ ) are given in parentheses (ZPE and BSSE corrected). The structures of the trans-trans and trans-cis dimers are presented in the Supporting Information. The notation of cis and trans conformers of formic acid follows ref 10 although the opposite notation can also be found in the literature.

have two hydrogen bonds (cc1, cc3, cc4, and cc5) and one structure has a single $\mathrm{O}-\mathrm{H} \cdots \mathrm{O}$ hydrogen bond (cc2). Three structures (cc1, cc2, and cc5) have similar interaction energies $\left(-26.9,-27.2\right.$, and $-27.0 \mathrm{~kJ} \mathrm{~mol}^{-1}$, respectively). These systems have the $\mathrm{O}-\mathrm{H} \cdots \mathrm{O}$ hydrogen bonds to the terminal oxygen. The $\mathrm{O}-\mathrm{H} \cdots \mathrm{O}$ hydrogen bond is significantly longer in cc5 than in cc2 (by $0.45 \AA$ ); nevertheless, this does not make a difference in the interaction energies because of the stabilization by the second $\mathrm{C}-\mathrm{H} \cdots \mathrm{O}$ bond in $\mathrm{cc5}$. The ccl dimer has two hydrogen bonds $[1.867 \AA(\mathrm{O}-\mathrm{H} \cdots \mathrm{O})$ and 2.765 $\AA(\mathrm{C}-\mathrm{H} \cdots \mathrm{O})]$ and interaction energy $-26.9 \mathrm{~kJ} \mathrm{~mol}^{-1}$. The symmetrical dimer cc3 with two $\mathrm{C}-\mathrm{H} \cdots \mathrm{O}$ hydrogen bonds $(2.37 \AA$ ) is the weakest structure (interaction energy $-16.9 \mathrm{~kJ}$ $\left.\mathrm{mol}^{-1}\right)$. The geometries of FA molecules are not changed significantly in the dimers. For example, the $\mathrm{O}-\mathrm{H}$ bond elongates by ca. $0.1 \AA$ in $\mathrm{cc} 1, \mathrm{cc} 2$, and cc3 compared to the cisFA monomer, and the $\mathrm{C}=\mathrm{O}$ bond involved in the hydrogen bond slightly elongates from 1.197 to $1.200 \AA$ A Practically the same changes in the bond lengths are found for the dimers of cis-HCOOD.

Table 1 shows the calculated vibrational spectra of the ciscis dimers of deuterated FA (HCOOD). We discuss the vibrational spectra for HCOOD in detail because this species is used in the present experiments. The calculated frequencies of the trans- and cis-FA monomers ( $\mathrm{HCOOH}$ and $\mathrm{HCOOD}$ ) are given in the Supporting Information (Table S1). For cc1, cc2, and $\mathrm{cc5}$, where the $\mathrm{O}-\mathrm{D}$ bonds are involved in intermolecular interaction, the $\mathrm{O}-\mathrm{D}$ stretching $(\nu \mathrm{OD})$ and torsional $(\tau \mathrm{COD})$ modes are the most sensitive to the complexation. A large red shift of $\nu \mathrm{OD}$ is predicted for these dimers (from ca. -130 to $-185 \mathrm{~cm}^{-1}$ ). The cc4 dimer is characterized by a smaller red shift of ca. $-50 \mathrm{~cm}^{-1}$ for the bonded OD stretching mode. The shifts for the uncomplexed $\nu \mathrm{OD}$ mode are less than $10 \mathrm{~cm}^{-1}$. For all dimers except cc4, the torsional modes exhibit blue shifts (up to $+186.7 \mathrm{~cm}^{-1}$ in $\mathrm{cc} 5$ ). The $\nu \mathrm{CH}$ modes involved in hydrogen bonding (cc1, cc3, cc4, and cc5) are blue-shifted from +34.7 (cc5) to +45.7 (cc1) $\mathrm{cm}^{-1}$. For the $\mathrm{cc} 3$ and $\mathrm{cc} 4$ dimers,

Table 1. Calculated Characteristic Frequencies $\left(\right.$ in $\mathrm{cm}^{-1}$ ), Intensities (in $\mathrm{km} \mathrm{mol}^{-1}$, in Parentheses), and Complexation-Induced Shifts (in $\mathrm{cm}^{-1}$ ) of the cis-cis HCOOD Dimers

\begin{tabular}{|c|c|c|c|c|c|}
\hline assignment & $\mathrm{ccl}$ & $\mathrm{cc} 2$ & $\operatorname{cc} 3$ & $\operatorname{cc} 4$ & $\operatorname{cc} 5$ \\
\hline \multirow[t]{4}{*}{$\nu \mathrm{CH}$} & $3091.7(41.1)$ & $3090.6(42.24)$ & $3092.4(0.0)$ & $3083.4(41.7)$ & $3080.6(26.4)$ \\
\hline & +45.7 & +44.6 & +46.5 & +37.5 & +34.7 \\
\hline & $3050.3(56.8)$ & $3041.7(63.5)$ & $3090.9(25.4)$ & $3074.5(35.1)$ & $3044.5(59.0)$ \\
\hline & +4.4 & -4.2 & +45.0 & +28.6 & -1.4 \\
\hline \multirow[t]{3}{*}{$\nu \mathrm{OD}$} & $2797.2(68.8)$ & $2798.9(70.3)$ & $2801.9(0.0)$ & $2797.5(65.0)$ & $2799.1(70.4)$ \\
\hline & -6.5 & -4.8 & -1.8 & -6.2 & -4.6 \\
\hline & -128.5 & -137.9 & -2.1 & -49.7 & -183.4 \\
\hline \multirow[t]{4}{*}{$\nu \mathrm{C}=\mathrm{O}$} & $1810.4(329.5)$ & $1809.6(46.6)$ & $1808.0(550.8)$ & $1818.3(290.5)$ & $1808.2(155.9)$ \\
\hline & -11.0 & -11.7 & -13.4 & -3.1 & -13.2 \\
\hline & $1795.3(368.6)$ & $1796.2(757.8)$ & $1787.4(0.0)$ & $1805.0(302.9)$ & $1791.9(618.5)$ \\
\hline & -26.1 & -25.2 & -34.4 & -16.4 & -29.5 \\
\hline \multirow[t]{3}{*}{$\nu \mathrm{C}-\mathrm{O}$} & $1220.7(483.3)$ & $1217.6(532.3)$ & $1193.8(0.0)$ & $1195.9(358.5)$ & $1231.1(61.5)$ \\
\hline & +44.6 & +41.5 & +17.7 & +19.8 & +55.0 \\
\hline & +19.7 & +36.0 & -3.9 & -18.5 & +21.7 \\
\hline \multirow[t]{4}{*}{ OCO-CODdef. } & $664.3(6.0)$ & $665.2(4.1)$ & $642.1(16.8)$ & $661.2(14.9)$ & $678.8(7.0)$ \\
\hline & +30.5 & +31.4 & +8.3 & +27.4 & +45.0 \\
\hline & $642.7(12.1)$ & 642.5 (19.7) & $634.7(0)$ & $634.6(5.1)$ & $649.3(9.2)$ \\
\hline & +8.9 & +8.7 & +0.9 & +0.8 & +15.5 \\
\hline \multirow[t]{4}{*}{$\tau \mathrm{COD}$} & $580.0(40.1)$ & $588.4(39.1)$ & $417.9(63.8)$ & $500.8(29.0)$ & $590.3(36.0)$ \\
\hline & +176.4 & +184.8 & +14.3 & +97.8 & +186.7 \\
\hline & $416.1(36.1)$ & $420.1(36.1)$ & $417.4(0.0)$ & $375.6(33.1)$ & $423.2(33.9)$ \\
\hline & +12.5 & +16.5 & +13.8 & -28.0 & +19.6 \\
\hline
\end{tabular}


the $\nu \mathrm{C}-\mathrm{O}$ frequencies are blue-shifted (up to $+19.8 \mathrm{~cm}^{-1}$ in cc4) for one molecule and red-shifted for the other molecule (up to $-18.5 \mathrm{~cm}^{-1}$ in $\mathrm{cc} 4$ ). For the $\mathrm{cc} 1, \mathrm{cc} 2$, and $\mathrm{cc} 5$ dimers, both $\nu \mathrm{C}-\mathrm{O}$ stretching vibrations are blue-shifted (up to +55.0 $\mathrm{cm}^{-1}$ in $\mathrm{cc} 5$ ). The intensities of bonded $\nu \mathrm{OD}$ for all the structures are predicted to be much higher than that for free $\nu \mathrm{OD}$, which is a normal effect for red-shifted hydrogen bonds. Similar spectral trends are observed for the cis-cis dimers of $\mathrm{HCOOH}$ (see Table S2). The calculated spectra for the transtrans and trans-cis dimers of HCOOD are presented in Tables S3 and S4.

Two cis-cis dimers were previously calculated by Roszak et $\mathrm{al}^{21}$ In their calculations (MP2/aug-cc-pVTZ), the FAD4 structure with an interaction energy of $-30.9 \mathrm{~kJ} \mathrm{~mol}^{-1}$ corresponds to the ccl dimer with an interaction energy $-26.9 \mathrm{~kJ} \mathrm{~mol}^{-1}$ in our notation. The second reported cis-cis dimer FAD5 $\left(-24.4 \mathrm{~kJ} \mathrm{~mol}^{-1}\right)$ is structurally similar to cc4 in our notation $\left(-21.1 \mathrm{~kJ} \mathrm{~mol}^{-1}\right)$. To the best of our knowledge, the other structures found in the present work $(\mathrm{cc} 2, \mathrm{cc} 3$, and cc5) have not previously been calculated.

\section{EXPERIMENTAL DETAILS}

The gaseous samples were prepared by mixing deuterated formic acid HCOOD (IT Isotop, 95-98\%), with argon (AGA, $99.9999 \%)$, typically in the 1:800 proportion. The matrices were deposited onto a CsI substrate at $12-25 \mathrm{~K}$ in a closed cycle helium cryostat (Sumitomo Heavy Industries). The achieved degree of deuteration of FA in matrices exceeded $80 \%$. The IR absorption spectra were measured with a Nicolet SX-60 FTIR spectrometer at $4.3 \mathrm{~K}$ using a liquid-nitrogen-cooled MCT detector and a $\mathrm{KBr}$ beam splitter (resolution of 0.25 $\mathrm{cm}^{-1}$ ). Typically 500 interferograms were coadded. Pulsed IR light (ca. $5 \mathrm{~ns}, 10 \mathrm{~Hz}$ ) from an optical parametric oscillator (OPO Sunlite with IR extension, Continuum) was used to convert the trans conformer to the cis form by exciting the $\nu \mathrm{OD}+\nu \mathrm{C}=\mathrm{O}$ combination mode at $4382 \mathrm{~cm}^{-1}$. 00

\section{EXPERIMENTAL RESULTS AND DISCUSSION}

trans-trans Dimers. The known bands of trans-HCOOD monomer dominate in the spectra after deposition (Figure 2,

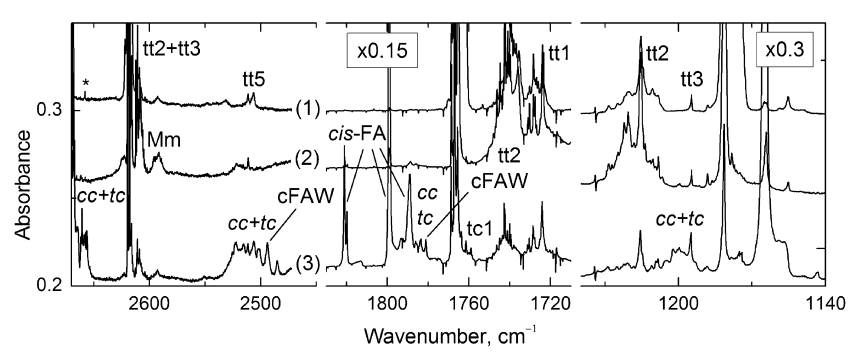

Figure 2. $\mathrm{OD}, \mathrm{C}=\mathrm{O}$, and $\mathrm{C}-\mathrm{O}$ stretching bands of $\mathrm{HCOOD}$ in an argon matrix. Shown are the results of deposition [trace 1], annealing at $34 \mathrm{~K}$ of matrices containing trans-FA [trace 2] and cis-FA [trace 3]. Mm marks the band of higher HCOOD multimers, $\mathrm{cc}$ and tc denote various cis-cis and trans-cis dimers, cFAW stands for the cisHCOOD $\cdots \mathrm{D}_{2} \mathrm{O}$ complex. The spectra were measured at $4.3 \mathrm{~K}$. Water impurity $\left(D_{2} \mathrm{O}\right)$ band is marked with asterisk.

trace 1 and Table $S 1) .{ }^{16,28,40}$ In addition, absorptions of several trans - trans dimers ( $\mathrm{tt} 1, \mathrm{tt} 2, \mathrm{tt} 3$, and $\mathrm{tt} 5$ ) are observed (Table 2 and Table S3). The assignment of these trans-trans dimers of HCOOD is done by analogy with the trans-trans dimers of $\mathrm{HCOOH}{ }^{17,31}$
Upon annealing above $27 \mathrm{~K}$, the bands of the trans-HCOOD monomer and $\mathrm{tt} 5$ dimer decrease in intensity and the bands of the $\mathrm{tt} 1$ and $\mathrm{tt} 2$ dimers grow (Figure 2, trace 2), similar to the case of $\mathrm{HCOOH} .{ }^{17,20,27,31}$ Annealing at $34 \mathrm{~K}$ vanishes the tt5 band at $2506.4 \mathrm{~cm}^{-1}$ completely, indicating the conversion of tt5 to more stable trans-trans structures. The weak broad absorption at ca. $2595 \mathrm{~cm}^{-1}$ probably belongs to FA trimers and/or higher aggregates as it grows up at higher FA concentrations and higher annealing temperatures. Upon annealing at $34 \mathrm{~K}$, the $\nu \mathrm{OD}$ and $\nu \mathrm{C}=\mathrm{O}$ bands of tt2 are shifted from 2610.0 and $1739.4 \mathrm{~cm}^{-1}$ to 2612.1 and 1742.6 $\mathrm{cm}^{-1}$, respectively. A band at $2511 \mathrm{~cm}^{-1}$ usually appears close to the $\mathrm{tt} 5$ band at $2506.4 \mathrm{~cm}^{-1}$ after deposition, and it does not change much upon annealing. This band seems to originate from a complex of trans-FA but we have no definite assignment for this band. This band may originate from the tt 5 dimer in a stable matrix configuration or tt4 dimer; however, this is not supported in other spectral regions. In any case, the $2511 \mathrm{~cm}^{-1}$ band is not connected with the cis-FA dimers that are the subject of the present work.

Dimers Containing the Higher-Energy Conformer. Vibrational excitation of the trans-HCOOD monomer at $4382 \mathrm{~cm}^{-1}(\nu \mathrm{OD}+\nu \mathrm{C}=\mathrm{O}$ combination mode $)$ efficiently produces cis-HCOOD (conversion up to $>90 \%$ ). Upon annealing above $27 \mathrm{~K}$, dimerization involves cis-FA and new bands appear in the spectrum as compared to the matrices containing entirely trans-FA (Figure 2, trace 3 ). In the OD stretching region, the annealing produces new bands in the $2662-2656 \mathrm{~cm}^{-1}$ (close to the cis monomer) and 2525-2485 $\mathrm{cm}^{-1}$ spectral regions. In addition, a band at $2494 \mathrm{~cm}^{-1}$ increases in intensity, which seems to correlate with the presence of water in the matrix $\left(\mathrm{D}_{2} \mathrm{O}\right)$.

The bands at $2662-2656 \mathrm{~cm}^{-1}$ are red-shifted from $\nu \mathrm{OD}$ of the cis-FA monomer by ca. -7 to $-13 \mathrm{~cm}^{-1}$; that is, they originate from the free OD stretching modes of the cis subunits in the dimers. The bands at $2525-2485 \mathrm{~cm}^{-1}$ are substantially red-shifted relative to the cis- and trans-FA monomers, showing that these bands are from the hydrogen-bonded OD modes. These large red shifts are from ca. -144 to $-184 \mathrm{~cm}^{-1}$ and from -93 to $-133 \mathrm{~cm}^{-1}$ as counted from the cis- and trans-FA monomers, respectively. In different experiments, the relative intensities of these bands vary but their positions are unchanged. The bands associated with the presence of cis-FA are suitable for a number of cis-cis and trans-cis dimers. The theory predicts spectral shifts from -4.6 to $-6.5 \mathrm{~cm}^{-1}$ for free and from -128.5 to $-183.4 \mathrm{~cm}^{-1}$ for the bonded OD stretching mode in the $c c 1, c c 2$, and cc5 dimers (Table 1), the most strongly bound cis-cis structures, which is in agreement with the experimental values. The cc3 and cc4 dimers have relatively small shifts $(-1.8 /-2.1$ and $-6.2 /-49.7$ $\mathrm{cm}^{-1}$, respectively) and cannot produce the strongly shifted bands at $2525-2485 \mathrm{~cm}^{-1}$. For the trans-cis dimers, structures tc 1, tc 4 , and tc5 are predicted to have absorptions slightly shifted from cis-FA monomer (from -0.6 to $-3.3 \mathrm{~cm}^{-1}$ ). The tc1 and tc4 structures are not suitable for bands observed at $2485-2525 \mathrm{~cm}^{-1}$ in the bonded $\nu \mathrm{OD}$ region due to the calculated shifts for the trans unit: -259.5 and $-4.1 \mathrm{~cm}^{-1}$, respectively (Table S4). The other trans-cis dimers (tc2, tc3, and tc5) can absorb at about $2500 \mathrm{~cm}^{-1}$ based on the ab initio calculations (Table S4) and experiments with $\mathrm{HCOOH} .{ }^{31} \mathrm{~A}$ broad band at $2425.4 \mathrm{~cm}^{-1}$ shifted from the cis-FA frequency by $-243.3 \mathrm{~cm}^{-1}$ may be the second OD stretching mode of dimer $\mathrm{tc} 2$. A broad band at $\sim 2340 \mathrm{~cm}^{-1}$ suggests the presence of the 
Table 2. Experimental Characteristic Frequencies and Experimental and Calculated Complexation-Induced Shifts (in $\left.\mathrm{cm}^{-1}\right) \mathrm{of}^{-}$ the HCOOD and $\mathrm{HCOOH}$ trans-trans $\left(\mathrm{tt} 1, \mathrm{tt} 2\right.$, $\mathrm{tt} 3$, and tt5) and trans-cis (tc1, tc2, tc3, and tc5) Dimers in an Argon Matrix ${ }^{a}$

\begin{tabular}{|c|c|c|c|c|c|c|c|}
\hline \multirow[b]{3}{*}{ dimer } & \multirow[b]{3}{*}{ assignment } & \multicolumn{3}{|c|}{ HCOOD } & \multicolumn{3}{|c|}{$\mathrm{HCOOH}$} \\
\hline & & \multirow{2}{*}{$\frac{\text { calculated }}{\text { shift }}$} & \multicolumn{2}{|c|}{ experiment } & \multirow{2}{*}{$\frac{\text { calculated }^{b}}{\text { shift }}$} & \multicolumn{2}{|c|}{ experiment $^{c}$} \\
\hline & & & frequency & shift & & frequency & shift \\
\hline \multirow[t]{6}{*}{$\mathrm{tt} 1$} & $\nu \mathrm{OD} / \nu \mathrm{OH}$ & -333.6 & 2271.8 & -346.2 & -462.8 & 3072 & -478 \\
\hline & & & 2259.4 & -358.6 & & & \\
\hline & $\nu \mathrm{C}=\mathrm{O}$ & -22.1 & 1724.1 & -43.1 & -21.7 & 1728 & -39 \\
\hline & $\nu \mathrm{C}-\mathrm{O} /$ & +96.1 & 1265.3 & +84.3 & +133.8 & 1224 & +120 \\
\hline & $\mathrm{CO}-\mathrm{COHdef}$. & & & & & 1225 & +121 \\
\hline & $\tau \mathrm{COD} / \tau \mathrm{COH}$ & +144.6 & 660.0 & +153.3 & +338.9 & 947 & +312 \\
\hline \multirow[t]{13}{*}{$\mathrm{tt} 2$} & $\nu \mathrm{OD} / \nu \mathrm{OH}$ & -5.6 & 2612.1 & -5.9 & -7.7 & 3540 & -10 \\
\hline & & -237.8 & 2610.0 & -8.0 & -332.9 & 3184 & -366 \\
\hline & & & 2365.7 & -252.3 & & 3168 & -382 \\
\hline & & & 2355.7 & -262.3 & & 3154 & -396 \\
\hline & & & 2348.9 & -269.1 & & 3142 & -408 \\
\hline & & & & & & 3101 & -449 \\
\hline & $\nu \mathrm{C}=\mathrm{O}$ & -16.3 & 1739.4 & -27.8 & -15.0 & 1748 & -19 \\
\hline & & -53.1 & 1742.6 & -24.6 & & & \\
\hline & & & 1705.9 & -61.3 & & & \\
\hline & $\nu \mathrm{C}-\mathrm{O} /$ & +53.9 & 1228.0 & +46.3 & +82.0 & 1180 & +76 \\
\hline & $\mathrm{CO}-\mathrm{COHdef}$. & +38.0 & 1215.4 & +33.7 & +32.8 & 1131 & +27 \\
\hline & $\tau \mathrm{COD} / \tau \mathrm{COH}$ & +20.4 & 524.0 & +17.3 & +259.5 & 868 & +233 \\
\hline & & & & & +22.4 & 658 & +23 \\
\hline \multirow[t]{9}{*}{$\mathrm{tt} 3$} & $\nu \mathrm{OD} / \nu \mathrm{OH}$ & -1.8 & 2608.4 & -9.6 & -2.4 & 3537 & -13 \\
\hline & & -3.4 & & & -4.5 & & \\
\hline & $\nu \mathrm{C}=\mathrm{O}$ & -5.0 & & & -4.1 & 1765 & -2 \\
\hline & & -12.9 & & & -12.8 & & \\
\hline & $\nu \mathrm{C}-\mathrm{O} /$ & +9 & 1193.7 & +12 & +6.2 & 1114.6 & +11 \\
\hline & $\mathrm{CO}-\mathrm{COHdef}$. & & & & +8.0 & & \\
\hline & & & & & -19.6 & & \\
\hline & $\tau \mathrm{COD} / \tau \mathrm{COH}$ & & & & +8.0 & 661 & +26 \\
\hline & & & & & -40.4 & 667 & +32 \\
\hline \multirow[t]{6}{*}{$\mathrm{tt} 5$} & $\nu \mathrm{OD} / \nu \mathrm{OH}$ & -107.0 & 2506.4 & -111.6 & -4.4 & 3544 & -6 \\
\hline & & & & & -149.1 & 3387 & -163 \\
\hline & $\nu \mathrm{C}=\mathrm{O}$ & +5.3 & 1770.7 & +3.5 & +6.3 & 1774 & +7 \\
\hline & & -18.1 & 1753.4 & -13.8 & -16.1 & 1750 & -17 \\
\hline & $\nu \mathrm{C}-\mathrm{O} /$ & +37.0 & 1210.9 & +29.2 & +58.0 & 1154 & +51 \\
\hline & $\mathrm{CO}-\mathrm{COHdef}$. & & & & -44.5 & 1074 & -29 \\
\hline \multirow[t]{11}{*}{ tcl } & $\nu \mathrm{OD} / \nu \mathrm{OH}$ & -3.3 & 2661.7 & -7.0 & -4.6 & 3604 & -12 \\
\hline & & -259.5 & 2346.8 & -271.2 & & 3115 & -435 \\
\hline & & & 2341.8 & -276.2 & & 3081 & -469 \\
\hline & & & 2332.1 & -285.9 & -363.5 & 3074 & -476 \\
\hline & $\nu \mathrm{C}=\mathrm{O}$ & -40.1 & 1758.4 & $-40.9^{d}$ & -32.8 & 1767 & -41 \\
\hline & & -43.8 & 1718.0 & -49.2 & & & \\
\hline & $\nu \mathrm{C}-\mathrm{O} /$ & +40.5 & 1199.7 & +35.7 & +13.8 & 1259 & +10 \\
\hline & $\mathrm{CO}-\mathrm{COHdef}$. & +59.7 & & & +89.3 & 1186 & +82 \\
\hline & & & & & +40.1 & 1143 & +35.3 \\
\hline & $\tau \mathrm{COD} / \tau \mathrm{COH}$ & +176.0 & 659.2 & +152.5 & +269.0 & 875 & +240 \\
\hline & & & & & +36.1 & 550 & +45 \\
\hline \multirow[t]{6}{*}{ tc2 } & $\nu \mathrm{OD} / \nu \mathrm{OH}$ & -92.4 & 2522.1 & -95.9 & -128.7 & 3411 & -139 \\
\hline & & -198.1 & 2425.4 & -243.3 & -279.1 & & \\
\hline & $\nu \mathrm{C}=\mathrm{O}$ & -9.8 & 1782.3 & $-17.0^{d}$ & -9.3 & 1793 & -14 \\
\hline & & -38.0 & 1717.0 & -50.2 & -31.9 & & \\
\hline & $\nu \mathrm{C}-\mathrm{O} /$ & +54.9 & 1224.8 & +43.8 & +18.4 & 1241 & -2 \\
\hline & $\mathrm{CO}-\mathrm{COHdef}$. & +9.1 & 1196.8 & +32.8 & +63.6 & 1155 & +52 \\
\hline \multirow[t]{6}{*}{$\mathrm{tc} 3$} & $\nu \mathrm{OD} / \nu \mathrm{OH}$ & -6.7 & 2607.6 & -10.4 & -9.4 & 3363 & -253 \\
\hline & & -168.8 & 2492.0 & -176.7 & -236.0 & & \\
\hline & $\nu \mathrm{C}=\mathrm{O}$ & -14.3 & 1782.1 & $-17.2^{d}$ & -11.0 & 1787 & -20 \\
\hline & & -24.4 & 1734.5 & -32.7 & -23.3 & & \\
\hline & $\nu \mathrm{C}-\mathrm{O} /$ & +50.0 & 1217.7 & +36.0 & +109.3 & 1338 & +95 \\
\hline & $\mathrm{CO}-\mathrm{COHdef}$ & +30.6 & 1193.2 & +29.2 & +51.1 & 1151 & +48 \\
\hline
\end{tabular}


Table 2. continued

\begin{tabular}{|c|c|c|c|c|c|c|c|}
\hline \multirow[b]{3}{*}{ dimer } & \multirow[b]{3}{*}{ assignment } & \multicolumn{3}{|c|}{ HCOOD } & \multicolumn{3}{|c|}{$\mathrm{HCOOH}$} \\
\hline & & \multirow{2}{*}{$\begin{array}{c}\text { calculated } \\
\text { shift }\end{array}$} & \multicolumn{2}{|c|}{ experiment } & \multirow{2}{*}{$\frac{\text { calculated }^{b}}{\text { shift }}$} & \multicolumn{2}{|c|}{ experiment $^{c}$} \\
\hline & & & frequency & shift & & frequency & shift \\
\hline & & & & & +36.3 & & \\
\hline \multirow[t]{9}{*}{ tc5 } & $\nu \mathrm{OD} / \nu \mathrm{OH}$ & -3.1 & 2656.1 & -12.6 & & & \\
\hline & & -141.1 & 2525.5 & -92.5 & -197.6 & 3406 & -144 \\
\hline & & & 2523.6 & -94.4 & & & \\
\hline & & & 2515.2 & -102.8 & & & \\
\hline & & & 2512.0 & -106.0 & & & \\
\hline & $\nu \mathrm{C}=\mathrm{O}$ & -13.2 & 1784.0 & $-15.3^{d}$ & -14.2 & 1797 & -10 \\
\hline & & -12.0 & 1743.2 & -24.0 & -12.4 & 1726 & -41 \\
\hline & $\nu \mathrm{C}-\mathrm{O} /$ & +28.5 & 1202.5 & +20.8 & +3.2 & 1254 & +11 \\
\hline & CO-COHdef. & & & & +50.4 & 1158 & +55 \\
\hline
\end{tabular}

${ }^{a}$ The data for the cis subunit of the dimer are in italics. ${ }^{b}$ From ref $17 .{ }^{c}$ From refs 17 and $31 .{ }^{d}$ Spectral shift is calculated for the strongest Fermi resonance component of the cis conformer $\left(1799.3 \mathrm{~cm}^{-1}\right)$.

tcl dimer. This band overlaps with the absorption of $\mathrm{CO}_{2}$ present as an impurity. On the basis of the experiments with different amounts of water in the matrix, the $2494 \mathrm{~cm}^{-1}$ band observed in the bonded $\nu \mathrm{OD}$ region is assigned to the cisHCOOD $\cdots \mathrm{D}_{2} \mathrm{O}$ complex (Table 4).

In the $\nu \mathrm{C}=\mathrm{O}$ region, the bands connected with the presence of cis-FA are at 1786.1, 1785.6, 1784.0, 1778.7, 1759.0, and $1758.4 \mathrm{~cm}^{-1}$. The bands at 1786.1, 1785.6, 1784.0, and 1778.7 $\mathrm{cm}^{-1}$ (shifts $-13.2,-13.7,-15.8$, and $-20.6 \mathrm{~cm}^{-1}$ from cis-FA monomer) can in principle belong to various trans-cis and cis-cis dimers. The calculations predict shifts from -11.0 to $-13.2 \mathrm{~cm}^{-1}$ for the cis-cis dimers $\mathrm{cc} 1, \mathrm{cc} 2$, and $\mathrm{cc} 5$ and from -9.8 to $-14.3 \mathrm{~cm}^{-1}$ for the trans-cis dimers tc2, tc3, and tc5 (Table 1 and S4). The doublet at 1759.0 and $1758.4 \mathrm{~cm}^{-1}$ shifted by -40.9 and $-40.3 \mathrm{~cm}^{-1}$ and by -8.2 and $-8.8 \mathrm{~cm}^{-1}$ from cis-HCOOD and trans-HCOOD may correspond to the most stable cis-cis structures cc1 and cc2 and to the tc1 dimer (Table 1 and Table S4). The calculated spectral shifts of the trans-FA subunit are $-38.0,-24.4$, and $-12.0, \mathrm{~cm}^{-1}$ for the tc2, tc 3 , and tc5 structures, respectively. Thus, the observed doublet may also belong to the trans-FA subunit of the tc5 dimer whereas its origin from tc 2 and tc 3 is less probable. A band at $1781.0 \mathrm{~cm}^{-1}$ observed in this region is most probably due to the cis-HCOOD $\cdots \mathrm{D}_{2} \mathrm{O}$ complex (Table 4).

In the $\nu \mathrm{C}-\mathrm{O}$ region, the bands connected with the presence of cis-FA are at 1193.2, 1196.8, 1200.5, 1202.5, 1205.5, 1207.5, 1217.7 , and $1224.8 \mathrm{~cm}^{-1}$. These bands fit the cis-cis ( $\mathrm{cc} 1, \mathrm{cc} 2$, and $\mathrm{cc} 5$ ) and trans-cis (tc2, tc3, and tc5) dimers. The bands of the $t c 2$, tc 3 , and $t c 5$ structures are blue-shifted by $+9.1,+30.6$, and $+28.4 \mathrm{~cm}^{-1}$ from cis-FA and by $+54.9,+50.0$, and +28.5 $\mathrm{cm}^{-1}$ from trans-FA by theory. The tc1 dimer absorbs at 1199.7 $\mathrm{cm}^{-1}$ (see below). No definite bands of the new absorbers are observed in the torsional region, despite the relatively high absorption intensities predicted by theory.

At this stage, we can conclude that the new bands observed in the $\nu \mathrm{C}=\mathrm{O}$ and free $\nu \mathrm{OD}$ regions indicate that cis-FA participates in the corresponding absorbers because the transtrans FA dimers cannot absorb at these frequencies. However, a number of assignments to cis-cis and trans-cis dimers are possible.

Discrimination of cis-cis and trans-cis Dimers. The discrimination of cis-cis and trans-cis dimers can be done by using experiments with different proportions of the trans and cis conformers. As mentioned above, the trans-trans dimers dominate after annealing at $34 \mathrm{~K}$ of matrices containing entirely
trans-FA (see Figure 3, trace 1). When cis-FA molecules are present (amount $\sim 25 \%$ ), the 2661.7, 2522, and $2515.2 \mathrm{~cm}^{-1}$

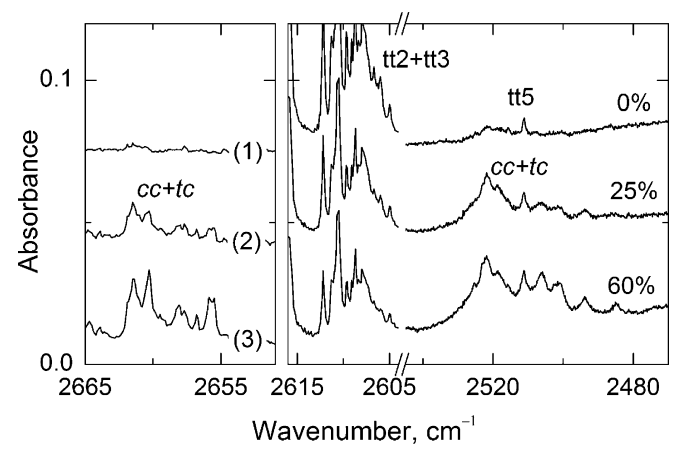

Figure 3. Annealing at $34 \mathrm{~K}$ of an argon matrices with different relative amounts of cis-HCOOD. $\mathrm{cc}$ and tc denote various cis-cis and transcis dimers. The spectra were measured at $4.3 \mathrm{~K}$. The proportion of cis$\mathrm{HCOOD}$ was measured after irradiation and annealing at $34 \mathrm{~K}$.

bands are most pronounced in the OD stretching region, the intensities of the tt 1 and tt 2 bands $\left(2271.8\right.$ and $2610.0 \mathrm{~cm}^{-1}$ ) decrease, and weak bands at $2500-2511$ and $2585.3 \mathrm{~cm}^{-1}$ are detected (Figure 3, trace 2). For the higher cis-HCOOD proportion $(\sim 60 \%)$, the bands at 2659.7, 2660.7, 2657.0, 2511.1, 2506.4, 2505.5, 2502.4, 2500.6, and $2485.3 \mathrm{~cm}^{-1}$ are relatively enhanced compared to the previously mentioned bands (Figure 3, trace 3). The bands enhanced at higher cisHCOOD proportions seem to belong to the cis-cis dimers (Table 3).

However, a more specific assignment of the observed bands to different cis-cis and trans-cis dimers is difficult based only on $a b$ initio calculations because the computed characteristic frequencies are close for the different cis-cis ( $c c 1, c c 2$, and cc5) and trans-cis (tc1, tc2, tc3, and tc5) structures. Among the cis-cis dimers, a substantial difference is predicted only for the bonded OD stretching mode of cc5 as compared to ccl and cc2 $\left(\sim 40 \mathrm{~cm}^{-1}\right)$. It follows that the strongly red-shifted OD stretching band at $2485.3 \mathrm{~cm}^{-1}$ most probably belongs to $\mathrm{cc} 5$. The most shifted broad band at $2425.4 \mathrm{~cm}^{-1}$ (shift -243.3 $\mathrm{cm}^{-1}$ ) seems to be characteristic for the tc2 dimer partially overlapped with a broad trans-HCOOD $\cdots \mathrm{D}_{2} \mathrm{O}$ absorption at $2412 \mathrm{~cm}^{-1}$ (Table 4). The other spectral features do not shed much light on the dimer structures. 
Table 3. Experimental Characteristic Frequencies and Experimental and Calculated Complexation-Induced Shifts (in $\mathrm{cm}^{-1}$ ) of the Observed cis-cis HCOOD Dimers

\begin{tabular}{|c|c|c|c|c|}
\hline \multirow[b]{2}{*}{ dimer } & \multirow[b]{2}{*}{ assignment } & \multirow{2}{*}{$\frac{\text { calculated }}{\text { shift }}$} & \multicolumn{2}{|c|}{ experiment } \\
\hline & & & frequency & shift \\
\hline \multirow[t]{15}{*}{$\mathrm{cc} 1 / \mathrm{cc} 2$} & $\nu \mathrm{OD}$ & $-4.8(\mathrm{cc} 2)$ & 2660.7 & -8.0 \\
\hline & & $-6.5(\mathrm{cc} 1)$ & 2659.7 & -9.0 \\
\hline & & $-128.5(\mathrm{ccl})$ & 2511.1 & -157.6 \\
\hline & & $-137.9(\mathrm{cc} 2)$ & 2506.4 & -162.3 \\
\hline & & & 2505.5 & -163.2 \\
\hline & & & 2502.4 & -166.3 \\
\hline & & & 2500.6 & -168.1 \\
\hline & $\nu \mathrm{C}=\mathrm{O}^{a}$ & $-11.0(\mathrm{cc} 1)$ & 1786.1 & -13.2 \\
\hline & & $-11.7(\mathrm{cc} 2)$ & 1785.6 & -13.7 \\
\hline & & $-26.1(\mathrm{cc} 1)$ & 1785.2 & -14.1 \\
\hline & & $-25.2(\mathrm{cc} 2)$ & & \\
\hline & $\nu \mathrm{C}-\mathrm{O}$ & $+44.6(\mathrm{ccl})$ & 1205.5 & +41.5 \\
\hline & & $+19.7(\mathrm{ccl})$ & 1200.5 & +37.5 \\
\hline & & $+41.5(\mathrm{cc} 2)$ & & \\
\hline & & $+36.0(\mathrm{cc} 2)$ & & \\
\hline \multirow[t]{6}{*}{$\operatorname{cc5}$} & $\nu \mathrm{OD}$ & -4.6 & 2657.0 & -11.7 \\
\hline & & -183.4 & 2485.3 & -183.4 \\
\hline & $\nu \mathrm{C}=\mathrm{O}^{a}$ & -13.2 & 1778.7 & -20.6 \\
\hline & & -29.5 & & \\
\hline & $\nu \mathrm{C}-\mathrm{O}$ & +55.0 & 1207.5 & +43.5 \\
\hline & & +21.7 & & \\
\hline
\end{tabular}

${ }^{a}$ Experimental spectral shift is calculated for the strongest Fermi resonance component of the cis conformer $\left(1799.3 \mathrm{~cm}^{-1}\right)$.

Selective Vibrational Excitation. More information to assign the cis-cis and trans-cis dimers is provided by selective vibrational excitation of these species. It is known that narrowband excitation of individual vibrational transitions is efficient to promote selective conformational changes in cryogenic matrices. ${ }^{12}$ Figure 4 presents the results of selective excitations of the annealing-produced structures at frequencies that correspond to the first $\mathrm{OD}$ stretching overtones (free vibrations) of the probable cis-cis dimers.

Excitation at $5221-5222 \mathrm{~cm}^{-1}$ approximately corresponds to the first overtone of the free OD stretching mode absorbing at $\sim 2656 \mathrm{~cm}^{-1}$. Upon this vibrational excitation, two sets of annealing-induced bands decrease in intensity. Different behavior of the bands under selective irradiation allows distinguishing absorptions from two species. One species absorbs at 2657.0 (shift $\left.-11.7 \mathrm{~cm}^{-1}\right), 2485.3\left(-183.4 \mathrm{~cm}^{-1}\right)$, $1778.7\left(-20.6 \mathrm{~cm}^{-1}\right)$, and $1207.5\left(+43.5 \mathrm{~cm}^{-1}\right) \mathrm{cm}^{-1}$, and the calculated spectral shifts strongly suggest that these bands originate from the cc5 dimer (Table 3). The second set includes bands at 2656.1, 2525.5, 2523.6, 2515.2, 2512.0, $1784.0,1743.2$, and $1202.5 \mathrm{~cm}^{-1}$, i.e. shifted by ca. -13 and

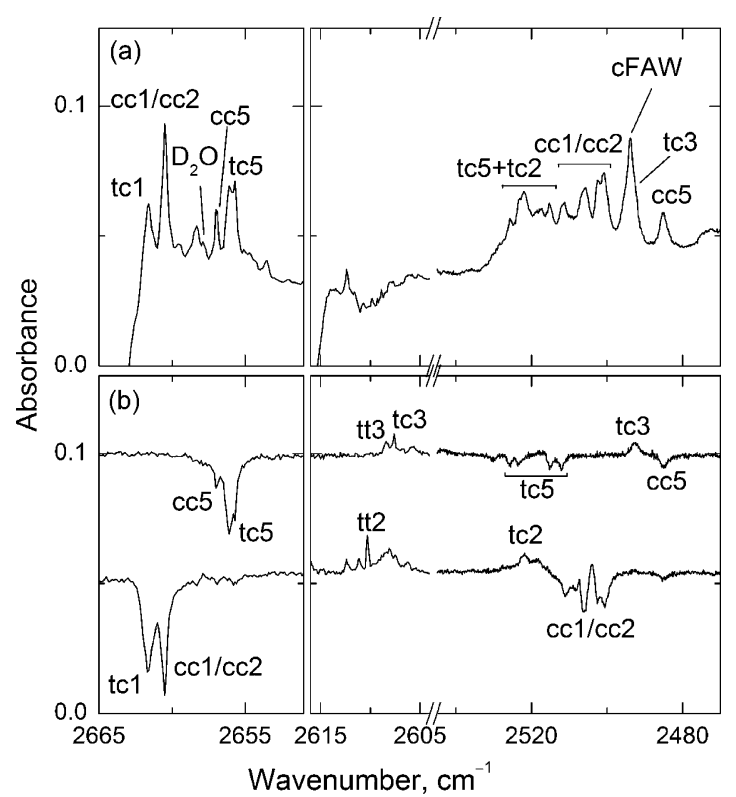

Figure 4. (a) Difference spectrum showing the result of annealing at $34 \mathrm{~K}$ of an argon matrix containing cis-HCOOD. (b) Difference spectra showing the results of excitations at 5221 and $5231 \mathrm{~cm}^{-1}$ (upper and lower traces, respectively). The wavenumber scales are different in the three spectral regions. cFAW stands for the cis$\mathrm{HCOOD} \cdots \mathrm{D}_{2} \mathrm{O}$ complex. The spectra were measured at $4.3 \mathrm{~K}$.

$-100 \mathrm{~cm}^{-1}$ for $\nu \mathrm{OD}$ (counted from cis-FA and trans-FA, respectively), by -15.5 and $-25 \mathrm{~cm}^{-1}$ for $\nu \mathrm{C}=\mathrm{O}$ (counted from cis-FA and trans-FA, respectively), and by $+20.8 \mathrm{~cm}^{-1}$ for $\nu \mathrm{C}-\mathrm{O}$ (from trans-FA), and this is assigned to the tc 5 structure (Table 2).

Excitation at $5231 \mathrm{~cm}^{-1}$ approximately corresponds to the first overtone of the free OD stretching mode at $\sim 2660 \mathrm{~cm}^{-1}$. Upon this vibrational excitation, a number of bands decrease in intensity, including the OD stretching band at 2660.7, 2659.7, $2511.1,2506.4,2505.5,2502.4$, and $2500.6 \mathrm{~cm}^{-1}$, the $\mathrm{C}=\mathrm{O}$ stretching bands at 1786.1, 1785.6, and $1785.2 \mathrm{~cm}^{-1}$, and the $\mathrm{C}-\mathrm{O}$ stretching bands at 1205.5 and $1200.5 \mathrm{~cm}^{-1}$. Thus, the experimental $\mathrm{OD}$ and $\mathrm{C}=\mathrm{O}$ stretching bands are red-shifted by -8.0 and -9.0 (free $\nu \mathrm{OD}$ ), $-157.6,-162.3,-163.2,-166.3$, and -168.1 (bonded $\nu \mathrm{OD}$ ), and $-13.2,-13.7$, and -14.1 $(\nu \mathrm{C}=\mathrm{O}) \mathrm{cm}^{-1}$ whereas the computational shifts of the $\mathrm{ccl}$ and cc2 dimer are -6.5 (cc1) and -4.8 (cc2) for free $\nu \mathrm{OD},-128.5$ (cc1) and $-137.9(\mathrm{cc} 2) \mathrm{cm}^{-1}$ for bonded $\nu \mathrm{OD}$, and -11.0 (cc1), -11.7 (cc2), -26.1 ( $\mathrm{cc} 1)$, and $-25.2(\mathrm{cc} 2) \mathrm{cm}^{-1}$ for the $\mathrm{C}=\mathrm{O}$ stretching modes. For the $\mathrm{C}-\mathrm{O}$ stretching mode, the calculations predict blue shifts $+44.6(\mathrm{cc} 1),+19.7(\mathrm{cc} 1),+41.5$ (cc2), and $+36.0(\mathrm{cc} 2) \mathrm{cm}^{-1}$ whereas the experimental values are +41.5 and $+37.5 \mathrm{~cm}^{-1}$. All shifts are counted from the cis-

Table 4. Experimental Characteristic Frequencies and Experimental and Calculated Complexation-Induced Shifts (in $\mathrm{cm}^{-1}$ ) of $^{-}$ the $\mathrm{HCOOD} \cdots \mathrm{D}_{2} \mathrm{O}$ and $\mathrm{HCOOH} \cdot{ }^{\cdots} \mathrm{H}_{2} \mathrm{O}$ Complexes

\begin{tabular}{|c|c|c|c|c|c|c|c|c|c|c|c|c|}
\hline \multirow[b]{2}{*}{ mode } & \multicolumn{3}{|c|}{ trans $-\mathrm{HCOOD} \cdots \mathrm{D}_{2} \mathrm{O}$} & \multicolumn{3}{|c|}{ trans $-\mathrm{HCOOH} \cdots \mathrm{H}_{2} \mathrm{O}^{a}$} & \multicolumn{3}{|c|}{ cis-HCOOD $\cdots \mathrm{D}_{2} \mathrm{O}$} & \multicolumn{3}{|c|}{ cis- $\mathrm{HCOOH} \cdots \mathrm{H}_{2} \mathrm{O}^{a}$} \\
\hline & freq. exp. & shift exp. & shift calc. & freq. exp. & shift exp. & shift calc. & freq. exp. & shift exp. & shift calc. & freq. exp. & shift exp. & shift calc. \\
\hline$\nu \mathrm{OD} / \nu \mathrm{OH}$ & 2412 & -206 & -196.6 & 3212 & -339 & -357 & 2494 & -147.7 & -136.4 & 3386 & -230 & -236 \\
\hline$\nu \mathrm{C}=\mathrm{O}$ & 1730 & -37.2 & -36.5 & 1737 & -9 & -3 & 1781.0 & -18.3 & -20.1 & 1786 & -21 & -21 \\
\hline$\nu \mathrm{C}-\mathrm{O} /$ & & & +48.4 & 1172 & +69 & +86 & & & +28.1 & 1342 & +93 & +90 \\
\hline def. & & & & & & & & & & 1189 & +34 & +54 \\
\hline
\end{tabular}

${ }^{a}$ From ref 43 . 
FA conformer. As suggested above, these bands could belong to the $c c 1$ and/or cc2 dimers. The discrimination of these two structures is very conditional and may be confused because all characteristic bands are very close. The second plausible explanation is that the observed bands are different matrix sites of one of these cis-cis structures. Excitation at $5231 \mathrm{~cm}^{-1}$ also affects the bands of the tcl dimer at 2661.7, 1758.4, and 1199.7 $\mathrm{cm}^{-1}$ (see below). The fundamental $\nu \mathrm{OD}$ band of the $\mathrm{cc} 1 / \mathrm{cc} 2$ dimer is very close to that of $\mathrm{tcl}$ and excitation at the first $\nu \mathrm{OD}$ overtone affects the cis-FA units in both dimers.

A band at $2658.0 \mathrm{~cm}^{-1}$ remains unassigned. It does not change much upon annealing and irradiations. This absorption seems to originate from a complex or dimer of cis-FA but we have no definite candidates for it.

Due to the high stability of cis-HCOOD, ${ }^{16}$ some amount of this species is formed during the FTIR measurements. Hence, traces of the tcl dimer could be found in the spectra after annealing at $34 \mathrm{~K}$ even in experiments without selective vibrational excitation of trans-FA.

Light-Induced Conformational Changes. A number of light-induced conformational changes were observed providing further information on different dimeric structures and supporting our assignments. First, we excited the tt2 dimer at $5134-5136 \mathrm{~cm}^{-1}$, which approximately corresponds to the free $\nu \mathrm{OD}$ overtone of $\mathrm{tt} 2$ with the fundamental absorption at 2612.1 $\mathrm{cm}^{-1}$. Upon this excitation, the $\mathrm{tt} 2$ concentration decreases and a number of bands rise (2661.7, 2340, 1758.4, 1718.0, and $\left.1199.7 \mathrm{~cm}^{-1}\right)$. Analysis shows that the rising bands belong to the tcl dimer (Table 2). A similar tt2-to-tc1 conversion was previously achieved for $\mathrm{HCOOH}$ by vibrational excitation at $3540 \mathrm{~cm}^{-1}$, which is free $\nu \mathrm{OH}$ of the $\mathrm{tt} 2$ dimer. ${ }^{17,30}$

The IR-induced decomposition of the cis-cis dimers is accompanied by the appearance of various trans-cis dimers. The bands growing upon excitation of $\mathrm{cc} 5$ at $5221 \mathrm{~cm}^{-1}$ probably belong to the tc3 dimer previously assigned for $\mathrm{HCOOH}$ (Table 2), ${ }^{31}$ which suggests a light-induced conformational change from $\operatorname{cc5}$ to tc3 (Figure 5a). These

(a)

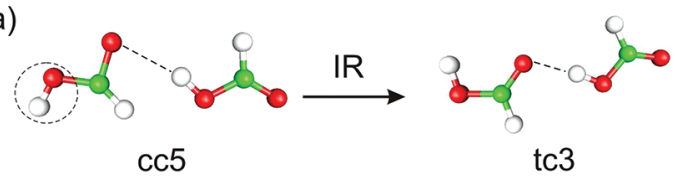

(b)

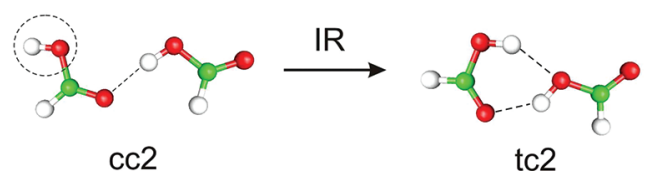

Figure 5. Most probable IR-induced processes for the cis-cis HCOOD dimers. The excitations are created at the first overtones of the free OD stretching modes (marked by circles).

two dimers differ mainly by orientation of the free $\mathrm{D}$ atom with respect to the $\mathrm{C}-\mathrm{O}$ bond, which makes this process very reasonable. Thus, the observed light-induced process supports our assignment for the cc5 and tc 3 dimers.

In addition, bands at 2608.4 and $1193.7 \mathrm{~cm}^{-1}$ rise upon excitation at $5221 \mathrm{~cm}^{-1}$, and they are assigned to the $\mathrm{tt} 3$ dimer. For the $\mathrm{tt} 3$ dimer, the complexation-induced shifts of the $\mathrm{C}-\mathrm{O}$ stretching mode are +9 (calculation) and $+12 \mathrm{~cm}^{-1}$ (experiment). The experimental shift of the OD stretching mode of $\mathrm{tt} 3$ $\left(-9.6 \mathrm{~cm}^{-1}\right)$ agrees well with the corresponding value for $\mathrm{HCOOH}\left(-13 \mathrm{~cm}^{-1}\right){ }^{17}$ The calculations give no alternative candidates for these experimental absorptions. The $\mathrm{C}=\mathrm{O}$ stretching mode of the tt3 structure is not observed probably due to overlapping with the strong $\nu \mathrm{C}=\mathrm{O}$ band of trans-FA monomer; indeed, for the tt3 dimer of $\mathrm{HCOOH}$ it is redshifted by $-2 \mathrm{~cm}^{-1}$. ${ }^{17}$ The $\nu \mathrm{C}=\mathrm{O}$ band rising upon excitation at $5221 \mathrm{~cm}^{-1}$ and red-shifted from trans-HCOOD monomer by ca. $-30 \mathrm{~cm}^{-1}\left(1735 \mathrm{~cm}^{-1}\right)$ is difficult to assign to the $\mathrm{tt} 3$ based on the calculations because the computational shift for the tt3 dimer is $-13 \mathrm{~cm}^{-1}$; hence, the assignment of this band is an open question. The $\mathrm{tt} 3$ dimer is probably formed from tc5 excited at $5221 \mathrm{~cm}^{-1}$.

Upon excitation at $5231 \mathrm{~cm}^{-1}$, the most probable product of cc2 is the tc2 dimer because the main difference between these two structures is in the orientation of the excited OD group (Figure 5b). Most of the observed tc2 bands fit well the theoretical results. Two bands at 2522.1 (shift -95.9 from trans-FA) and 2425.4 ( -243.3 from cis-FA) $\mathrm{cm}^{-1}$ rise in the bonded $\nu \mathrm{OD}$ region (Table 2). Two blue-shifted bands at 1196.8 (+32.8 from cis-FA) and $1224.8(+43.8$ from trans-FA) $\mathrm{cm}^{-1}$ rise synchronously in the $\nu \mathrm{C}-\mathrm{O}$ region. In the $\nu \mathrm{C}=\mathrm{O}$ region, the rising bands at 1782.3 and $1717.0 \mathrm{~cm}^{-1}$ are shifted by $-17.0 \mathrm{~cm}^{-1}$ from cis-FA and by $-50.2 \mathrm{~cm}^{-1}$ from trans-FA. The formation of the tc2 dimer in this IR-induced process suggests that the initial species is most probably cc2.

\section{CONCLUSIONS}

The present work has been focused on the preparation and identification of dimers composed of the higher-energy cis conformer of formic acid. Five stable cis-cis FA dimeric structures, their interaction energies, and vibrational spectra are obtained at the MP2/6-311++(2d,2p) level of theory (Figure 1 and Table 1). Three of them (cc2, cc3, cc5) are calculated for the first time.

The cis-cis dimers are prepared in argon matrices by a combination of vibrational excitation of trans-HCOOD (deuterated form) and thermal annealing. The experimental spectral shifts upon dimerization are in agreement with the $a b$ initio calculations (Tables 2 and 3). This is the first report on the experimental identification of dimers consisting of two higher-energy cis conformers of formic acid. In addition to the new cis-cis dimers ( $\mathrm{ccl} / \mathrm{cc} 2$ and $\mathrm{cc5} 5)$, we observe the formation of four trans-cis (tc1, tc2, tc3, and tc5) dimers and four trans-trans ( $\mathrm{tt} 1, \mathrm{tt} 2, \mathrm{tt} 3$, and $\mathrm{tt} 5)$ dimers previously identified for $\mathrm{HCOOH} .{ }^{17,31}$ The excitation of the first OD stretching overtone of the cis-cis dimers leads to the cis-totrans conformational changes, yielding the trans-cis dimers tc2 and tc3 (Table 2 and Figure 5).

Six trans-trans, six trans-cis (with the new structure obtained in the present work), and five cis-cis structures have been theoretically predicted so far for formic acid. Before our first work on this subject ${ }^{30}$ only two trans-trans dimers were experimentally known ( $t$ t 1 and $t \mathrm{t} 2) .{ }^{27}$ In ref 30 , we reported the first trans-cis dimer $(\mathrm{tcl})$. Later, we have additionally identified two trans-trans dimers ( $\mathrm{tt} 3$ and $\mathrm{tt} 6$ ) and one trans-cis dimer (tc4), ${ }^{17}$ and very recently we have added $\mathrm{tc} 2, \mathrm{tc} 3, \mathrm{tc} 5, \mathrm{tt} 4$, and $\mathrm{tt} 5$. $^{31}$ In the present work, we report several cis-cis ( $c c 1 / c c 2$ and $c c 5)$ dimers. Thus, six trans-trans dimers, five trans-cis dimers, and at least two (or three) cis-cis FA dimers have been experimentally found. The only structures which have not been experimentally observed are one trans-cis (tc6) and two cis-cis (cc3 and cc4) dimers. Thus, the majority of the predicted formic acid dimers have been experimentally 
characterized and the identification of all possible dimers of formic acid can be finished soon.

It should be finally noted that the structural assignments are not unambiguous in the case of FA dimers in matrices, and the most probable assignments are always proposed. Most importantly, the matrix effect on structure and spectra of the dimers can be substantial because the interaction potential is rather flat. In other words, the observed matrix-isolated dimers and their vibrational spectra probably differ from the species predicted in vacuum. For example, all predicted so far FA dimers are planar in vacuum; however, this is probably changed by a solid matrix. No theoretical estimations of this effect have been done, and this is a challenge for computational science. Another interesting question concerns the effect of anharmonicity on the vibrational spectra taking into account that the vast majority of calculations are done within the harmonic approximation.

\section{ASSOCIATED CONTENT}

\section{S Supporting Information}

Calculated structures and interaction energies of trans-trans and trans-cis HCOOD dimers, experimental and calculated spectra of trans- and cis-HCOOD, calculated spectra of the ciscis $\mathrm{HCOOH}$ dimers, trans-trans HCOOD dimers, and transcis HCOOD dimers. This material is available free of charge via the Internet at http://pubs.acs.org.

\section{AUTHOR INFORMATION}

\section{Corresponding Author}

*E-mail: leonid.khriachtchev@helsinki.fi.

\section{Notes}

The authors declare no competing financial interest.

\section{ACKNOWLEDGMENTS}

The work was supported by the Finnish Center of Excellence in Computational Molecular Science and by the Research Foundation of the University of Helsinki. CSC-IT Center for Science Ltd. is thanked for computational resources.

\section{REFERENCES}

(1) Ellder, J.; Friberg, P.; Hjalmarson, A.; Hoeglund, B.; Irvine, W. M.; Johansson, L. E. B.; Olofsson, H.; Rydbeck, G.; Rydbeck, O. E. H. Astrophys. J. 1980, 242, L93-L97.

(2) Irvine, W. M.; Friberg, P.; Kaifu, N.; Kitamura, Y.; Kawaguchi, K. Astrophys. J. 1989, 342, 871-875.

(3) Rodgers, S. D.; Charnley, S. B. Mon. Not. R. Astron. Soc. 2001, 320, 61-64.

(4) Largo, A.; Redondo, P.; Barrientos, C. Int. J. Quantum Chem. 2004, 98, 355-360. Hoyle, F.; Wickramasinghe, N. C. Nature 1976, $264,45-46$

(5) Gutowski, M.; Skurski, P.; Simons, J. J. Am. Chem. Soc. 2000, 122, 10159-10162.

(6) Ban, F. Q.; Gauld, J. W.; Boyd, R. J. J. Phys. Chem. A 2000, 104, 5080-5086.

(7) Keene, W. C.; Galloway, J. N. Tellus B 1988, 40, 322-324.

(8) Christian, T. J.; Kleiss, B.; Yokelson, R. J.; Holzinger, R.; Crutzen, P. J.; Hao, W. M.; Shirai, T.; Blake, D. R. J. Geophys. Res. 2004, 109, D02311.

(9) Rinsland, C. P.; Jones, N. B.; Connor, B. J.; Wood, S. W.; Goldman, A.; Stephen, T. M.; Murcray, F. J.; Chiou, L. S.; Zander, R.; Mahieu, E. J. Geophys. Res. 2002, 107, D4185.

(10) Hocking, W. H. Z. Naturforsch. A 1976, 31, 1113-1121.

(11) Pettersson, M.; Lundell, J.; Khriachtchev, L.; Räsänen, M. J. Am. Chem. Soc. 1997, 119, 11715-11716.
(12) Khriachtchev, L. J. Mol. Struct. 2008, 880, 14-22.

(13) Pettersson, M.; Maçôas, E. M. S.; Khriachtchev, L.; Lundell, J.; Fausto, R.; Räsänen, M. J. Chem. Phys. 2002, 117, 9095-9098.

(14) Lopes, S.; Domanskaya, A. V.; Fausto, R.; Räsänen, M.; Khriachtchev, L. J. Chem. Phys. 2010, 133, 144507.

(15) Marushkevich, K.; Khriachtchev, L.; Räsänen, M. J. Chem. Phys. 2007, 126, 241102

(16) Domanskaya, A.; Marushkevich, K.; Khriachtchev, L.; Räsänen, M. J. Chem. Phys. 2009, 130, 154509.

(17) Marushkevich, K.; Khriachtchev, L.; Lundell, J; Domanskaya, A.; Räsänen, M. J. Phys. Chem. A 2010, 114, 3495-3502.

(18) Qian, W.; Krimm, S. J. Phys. Chem. A 2001, 105, 5046-5053.

(19) Chocholousova, J.; Vacek, J.; Hobza, P. Phys. Chem. Chem. Phys. 2002, 4, 2119-2122.

(20) Olbert-Majkut, A.; Ahokas, J.; Lundell, J.; Pettersson, M. Chem. Phys. Lett. 2009, 468, 176-183.

(21) Roszak, S.; Gee, R. H.; Balasubramanian, K.; Fried, L. E. J. Chem. Phys. 2005, 123, 144702 .

(22) Turi, L. J. Phys. Chem. 1996, 100, 11285-11291.

(23) Yavuz, I.; Trindle, C. J. Chem. Theory Comput. 2008, 4, 533541.

(24) Ito, F. J. Chem. Phys. 2008, 128, 114310.

(25) Zielke, P.; Suhm, M. A. Phys. Chem. Chem. Phys. 2007, 9, 45284534.

(26) Balabin, R. M. J. Phys. Chem. A 2009, 113, 4910-4918.

(27) Gantenberg, M.; Halupka, M.; Sander, W. Chem.-Eur. J. 2000, 6, 1865-1869.

(28) Henderson, D. O. Doctoral Thesis, Texas Technical University, 1987.

(29) Maçôas, E. M. S.; Myllyperkiö, P.; Kunttu, H.; Pettersson, M. J. Phys. Chem. A 2009, 113, 7227-7234.

(30) Marushkevich, K.; Khriachtchev, L.; Lundell, J.; Räsänen, M. J. Am. Chem. Soc. 2006, 128, 12060-12061.

(31) Marushkevich, K.; Siltanen, M.; Räsänen, M.; Halonen, L.; Khriachtchev, L. J. Phys. Chem. Lett. 2011, 2, 695-699.

(32) Madeja, F.; Havenith, M.; Nauta, K.; Miller, R. E.; Chocholousova, J.; Hobza, P. J. Chem. Phys. 2004, 120, 10554-10560.

(33) Zhou, P. P.; Qiu, W. Y. ChemPhysChem 2009, 10, 1847-1858.

(34) Shimizu, H. Physica B\&C 1986, 139, 479-481.

(35) Goncharov, A. F.; Manaa, M. R.; Zaug, J. M.; Gee, R. H.; Fried, L. E.; Montgomery, W. B. Phys. Rev. Lett. 2005, 94, 065505.

(36) Hakala, M.; Marushkevich, K.; Khriachtchev, L.; Hämäläinen, K.; Räsänen, M. J. Chem. Phys. 2011, 134, 054506.

(37) Frisch, M. J.; Trucks, G. W.; Schlegel, H. B.; Scuseria, G. E.; Robb, M. A.; Cheeseman, J. R.; Zakrzewski, V. G.; Montgomery, J. A., Jr.; Stratmann, R. E.; Burant, J. C.; et al. Gaussian 03, revision C.02; Gaussian, Inc.: Wallingford, CT, 2004.

(38) Boys, S. F.; Bernardi, F. Mol. Phys. 1970, 19, 553-566.

(39) Zhou, Z. Y.; Shi, Y.; Zhou, X. M. J. Phys. Chem. A 2004, 108, 813-822.

(40) Marushkevich, K.; Khriachtchev, L.; Lundell, J; Domanskaya, A.; Räsänen, M. J. Mol. Spectrosc. 2010, 259, 105-110.

(41) Engdahl, A.; Nelander, B. J. Mol. Struct. 1989, 193, 101-109.

(42) Maçôas, E. M. S.; Khriachtchev, L.; Pettersson, M.; Juselius, J.; Fausto, R.; Räsänen, M. J. Chem. Phys. 2003, 119, 11765-11772.

(43) Marushkevich, K.; Khriachtchev, L.; Räsänen, M. J. Phys. Chem. A 2007, 111, 2040-2042. 